\title{
Access and Equity: The New South Wales Court Interpreter Service
}

\author{
Ian Dobinson \& Thomas Chiu ${ }^{\star}$
}

\section{Introduction}

Multiculturalism, as a policy, is central to many aspects of Australia's social, political and legal environments. A major turning point in Australia's political landscape and its approach to multiculturalism was the National Agenda for a Multicultural Society published in 1989. As part of this agenda the Federal Government introduced its Access and Equity Policy. From a legal perspective, this Policy emphasised an ideological commitment to 'equality before the law'. The Policy further recognised that certain sections of the community faced greater hardship than others in terms of their understanding of the Australian legal system and accordingly their ability to utilise the system to enforce and protect their rights. This was particularly true for those whose first language was not English and who, to varying degrees, lacked English language proficiency.

As Laster noted, however:

The failure of the legal system to recognize the full participation in the legal system by NESB (Non-English Speaking Background) people became a political embarrassment for governments committed to a 'justice' and 'equity' policy platform (1993:1).

The most visible failure in this regard was the lack of adequate court interpreter services. In 1991, the Commonwealth Attorney-General's Department published a report entitled Access to Interpreters in the Australian Legal System. The report concluded that:

Whilst much of the information is anecdotal, there is substantial evidence to suggest that, in cases where a witness has limited understanding of English, there has been a reluctance by some judges to allow an interpreter to be used.

This reflects the primary consideration in the exercise of the common law discretion that a witness with some understanding of English should not obtain an unfair advantage. A related concern has been to minimise the barriers to communication caused by the use of interpreters. Less attention has been given to the real risk that a witness with insufficient knowledge of English may not be able to adequately understand the questions put and convey the meanings he or she wishes to express.

At present the onus is on the person wishing to use an interpreter to establish that he or she has a need for one. The conclusion reached in this report is that there should be a prima facie right to an interpreter, and, in certain circumstances, to have one provide provided free of charge. That right should only be displaced if it can be established that the person has an adequate command of English (1991:36).

* Ian Dobinson and Thomas Chiu are currently senior lecturers at the Faculty of Law, University of Technology, Sydney. 
What followed, at both Federal and State levels, was legislation, policy and case law which created an apparent 'right to an interpreter' in legal proceedings. In NSW, for example, the government published the Charter of Principles for a Culturally Diverse Society (NSW Government:1993). The NSW Guide to Local Court Policies and Procedures states that:

The Attorney General's Department has a responsibility to ensure that the principles outlined in the NSW State Government's 'Charter of Principles for a Culturally Diverse Society' are reflected in our service delivery practices. To give weight to our responsibilities in delivering an equitable and accessible justice system to all citizens, the Department developed the 'Statement of Intent' to articulate the Department's commitment to implementation of the Charter. One of the primary objectives is: 'to improve communication between the Department and its clients by providing access to our bilingual and Aboriginal and Torres Strait Islander staff, professional interpreter services and our Language Link Resource Kit' (NSW Attorney General's Department (nd)).

In the NSW Guide, there is clear reference to the right to an interpreter and that court staff ensure that 'clients' are made aware of this right (See Section 1 Interpreters, Item 1.3). The Community Relations Commission and Principles of Multiculturalism Act 2000 further states that:
All individuals and institutions should respect and make provision for the culture, language and religion of others within an Australian legal and institutional framework where English is the common language (Part 1, S3(1), Principle 2).

While the 'right to an interpreter' is a significant development, Laster noted that the practical implementation of this 'right' has been 'less sure-footed' (1993:2).

In their Victorian study, Laster and Taylor analysed the court interpreter service in operation in the Victorian County Court. This involved interviews with prosecutors, defence counsel and interpreters in eight criminal trials. The findings noted that:

Many of the deficiencies blamed on individual interpreters, now and in the past, are the result of systemic problems, such as the lack of uniform education and testing to promote high levels of technical competence, and the failure to develop proper mechanisms for service delivery. Underlying these, of course, are inadequacies in the resources for legal interpreting services and levels of pay for interpreters (Laster \& Taylor 1994a:14).

Laster and Taylor also questioned the focus on court interpreters as this tended to divert attention from the provision of such services in other legal settings (1994a:128). This focus is, however, indicative of the political nature of Australia's approach to multiculturalism in the legal arena. As such, the recognition of the 'right to an interpreter' and the provision of such a service in the courtroom are seen to achieve 'access' and 'equity'.

While we accept the limitations of such a focus and the need to expand the provision of interpreter services to all stages of the legal process, the use of court interpreters continues to be seen as the primary form of assistance to NESB persons involved in the Australian criminal justice system. In this regard, the research outlined in this article focuses on the use of court interpreters in New South Wales' criminal cases.

It has been 14 years since the Commonwealth Attorney-General's Department published the report, Access to Interpreters in the Australian Legal System and 12 years since the NSW Charter. The question posed is the extent to which there has been significant change and development.

Laster and Taylor put forward a number of proposals as well as highlighting major shortfalls and problems (1994a). These can be grouped under four headings and the purpose of this article is to assess, in a preliminary sense, the current position regarding the court interpreter service in NSW criminal matters under these headings. The headings are: 
1. Access and the right to an interpreter.

2. Resourcing and associated logistical problems.

3. Professionalisation, education and training.

4. Quality and accuracy.

The discussion that follows is based on a series of interview's (face-to-face or by telephone) with a judge, a magistrate, four court administrators, two prosecutors from the Office of the Director of Public Prosecutions (DPP), a police prosecutor, a defence lawyer, a Legal Aid lawyer, an interpreter, a representative of the National Accreditation Authority for Translators and Interpreters (NAATI), a representative of the Australian Institute of lnterpreters and Translators (AUSIT) and two officers of the Community Relations Commission $(\mathrm{CRC})$. The interviews were unstructured and open-ended, the objective being to identify the principal issues affecting the current provision of court interpreters in NSW criminal cases and to subsequently use these findings to support and inform a much larger research project on this topic.

\section{New South Wales Court Interpreter Service}

The largest provider of court interpreters in NSW is the Community Relations Commission (CRC) (formerly the Ethnic Affairs Commission). From its 2002/3 Annual Report, it is noted that the CRC provided interpreter services for 19,398 assignments in 60 different languages (CRC 2002/3:122). It is not clear from the 2002/3 CRC statistics, but in previous years $90 \%$ of assignments were for the govemment and the majority of these were for criminal proceedings. Court interpreter services are arranged through a booking process. This may be initiated at the arrest/detention/interview stage where the need for an interpreter is identified by the police or requested by the person detained or being interviewed. If this occurs, then an interpreter, not necessarily the same one used in the police interview and interrogation will be booked for the first court appearance. This process will continue for all subsequent court appearances up to and including the trial, but it is again important to note, that the same interpreter will not necessarily be retained.

Where an offender is in custody, an interpreter will be booked for the first court appearance. This will also occur when an offender is bailed to appear before the court at a later date. In relation to a Local Court trial, the police prosecution division (Legal Services) will also identify the need for an interpreter to assist in the giving of testimony by relevant witnesses. In District Court trials, this will occur through the DPP. In circumstances involving the need for an interpreter for the accused and any witnesses, one interpreter will be used. In the case of multiple offenders who may appear together a number of interpreters may be used depending on availability. Based on the right of an accused to his/her own interpreter, the objective is to provide each defendant with an interpreter, although this may not be possible depending on interpreter availability. Such services are free. ${ }^{1}$

Where an individual is not arrested and is simply summonsed to appear before the Local Court, there are a variety of outcomes that can occur regarding the use of interpreters. First, an accused or witness can request that an interpreter be made available. Such requests may occur particularly where a private lawyer has been retained. It may not be apparent, however, that an interpreter is needed until the accused's or witness's first appcarance

1 The CRC supplies interpreter services to courts ot a 'fee exempt basis for: defendants in criminal matters; all domestic violence matters; chamber magistrate interviews in relation 10 criminal or Apprehended Violence Order (AVO) matters; and parties in care proceedings in the Children's Court. 
before the magistrate. Where a magistrate becomes aware of such a need, the case should be adjourned in order to make arrangements for a court interpreter. In this sense the magistrate not only has considerable discretion but will also require expertise in identifying such need.

At the District and Supreme Court levels, arrangements for interpreters are much more formalised. The need for a court interpreter(s) will have been identified at the initial arrest. Once the matter reaches trial, an attempt will be made to book an interpreter for the duration of the matter based on the estimated length of the trial. As will be discussed later, this sometimes causes problems where there is an overrun and, due to other bookings, the interpreter is unavailable to continue.

\section{1) Access and the Right to an Interpreter}

As noted above, there currently appears to be a 'right to an interpreter' in criminal cases. This 'right' can be traced to a variety of legislative sources ${ }^{2}$ as well as international treaties and conventions which stipulate such rights. ${ }^{3}$

The courts themselves have considcred this issue particularly where, on appeal, there has been suggestions of miscarriages of justice due to the failure to provide the accused with appropriate interpreter services (Ex parte Nguyen). The basis for the common law approach to the right to an interpreter in a criminal case can be traced to the English Court of Appeal decision in Lee Kun. Obiter in this case stated that all unrepresented defendants should be provided with an interpreter where there was a clear need to communicate the prosecution's case. Even where represented, the Court of Appeal noted that the safest course was to have the evidence interpreted. Failures in this regard, however, would not result in the proceedings being invalid, unless a substantial miscarriage of justice had taken place. While again only obiter, the High Court in Deirrich indicated its possible willingness to entertain appeals where the defendant had not had interpreter assistance.

A leading NSW decision on the 'right to an interpreter' is Adamopoulus. The judgment most quoted is that of Kirby $\mathrm{J}$ who stated that:

The mere fact that a person can sufficiently speak the English language to perform mundane or social tasks or even business obligations at the person's own pace does not necessarily mean that he or she is able to cope with the added stresses imposed by appearing as a witness in a court of law. Still more powerful are the reasons for affording a person the assistance of an interpreter if he or she must present the case without the help of legal counsel. Some of the earlier legal authorities about access to an interpreter reflect an attitude of a society, racially and linguistically homogeneous and often unsympathetic to the problems of others struggling in an alien environment. It is typical of a country with poor skills in languages other than English that even educated judicial officers sometimes show an intolerance to the predicament of parties and witnesses whose first language is not English and who seek the provision of an interpreter (at 77).

Kirby noted, however, that this does not give rise to 'a right to an interpreter' and that:

.....a discretion must always be reserved to the trial judge to balance the inconvenience occasioned by a late application for an interpreter; the possibility that the application has been made for extraneous or ulterior purposes; and an assessment that in the particular case an interpreter is not needed for the issues involved (at 78).

2 Sec for example s30 of the Commonwealth and New South Wales Evidence Acts 1995.

3 See for example the Mmernational Covenam on Civil and Political Rights. 
Adamopoulus is a civil case but the courts in NSW see it as applicable to criminal cases. This is only logical with there being even greater entitlement to interpreter assistance in criminal as compared to civil matters. It may be said that there is still no absolute 'right to an interpreter' but in practice judges and magistrates appear to err on the side of caution. This was certainly the view of both the District Court judge and Local Court Magistrate who were interviewed. Such an approach is also reflected in the NSW Guide to Local Court Policies and Procedures:

Court staff should err on the side of caution since failure to recognise the need for an interpreter may result in a miscarriage of justice (p 2).

An extremely important document in the NSW context is the Law Society's Guide to Best Practice for Lawyers Working with Interpreters and Translators in a Legal Environment (Law Society 1996). In Section 5, this Guide outlines the circumstances in which there is a right to an interpreter, noting that this right cannot be waived unless such person is represented and the judge is satisfied that the accused understands the substance of the proceedings (1996:6).

In terms of access to interpreter services, those interviewed outlined significant differences between the District and Local Courts. Both the District Court Judge and DPP prosecutor, for example, stated that there were few, if any, problems regarding access to court interpreter services. This was also confirmed by two District Court clerical officers. The District Court judge even indicated that he had ordered additional interpreters for one of his cases based on his own assessment of the need for this assistance.

At the Local Court level, the situation is significantly different. A senior Local Court clerk stated that he had no doubt that a significant proportion of defendants appearing before the NSW Local Courts were in need of but were not provided with interpreter services. There are a number of reasons for this. The first and perhaps most common is that the matter has proceeded by way of an unrepresented defendant pleading guilty. In these circumstances both the magistrate and prosecution may be unaware that the defendant needs interpreter assistance. If the defendant is represented, and no formal request is made by defence counsel, then it is similarly assumed that the defendant understands the nature of the charges, the proceedings and the likely penalties. As stated by the magistrate interviewed, however, it is his responsibility to ensure that the defendant does understand these matters and if not to adjourn the case so that a court interpreter can be obtained. It seems apparent, however, that the very nature of Local Court practice and need for a high turnover of cases is a significant impediment to access to interpreter services at this court level.

The senior Local Court clerk stated that many unrepresented, and in some cases even represented, defendants who have pleaded guilty, have not really undersiood the proceedings. The evidence for this, in his view, was that a number often come back to court to ask for an explanation of the penalty imposed and it is at this stage that it becomes clear that they had not really understood what was happening or the true consequences of their guilty plea.

In recognition of the needs of NESB individuals, a joint project between the NSW Attorney General's Department and the then Ethnic Affairs Commission (now CRC) was undertaken at Fairfield Local Court. Fairfield was chosen because it is a local government area with a particularly high proportion on non-English speaking residents. Based on 1996 Census statistics, the report noted that over 60 languages were spoken by residents, $31 \%$ of residents were from non-English speaking backgrounds and that they did not speak English 
at all or did not speak it well (NSW Government 1998:8). The provision of professional interpreting and language services was identified as one of the primary concerns in terms of 'access to justice' at the court.

The Fairfield Report identified the following factors as having a significant impact on the quality of service provision:

i) definition of an interpreter;

ii) use of non-professional and /or unaccredited persons as substitutes for interpreters;

iii) budget issues in the provision of professional interpreters;

iv) legal interpreter training;

v) specific needs of women of a non-English speaking background;

vi) co-ordination between agencies (1998:9).

The principal concerns with regard to the then interpreter services in criminal and domestic violence cases were:

i) non provision of interpreters for first appearance dates;

ii) interpreters not required for overnight custody matters;

iii) lack of co-ordination of interpreter services;

iv) one interpreter attending for both parties in domestic violence or family law cases (there was a perception among clients that an interpreter is such a situation may not be impartial);

v) use of unqualified and non-accredited people acting as interpreter (1998:22).

As a result of these findings, three new initiatives were introduced at Fairfield Court in 1996. These were the introduction of an Interpreter Booking Diary Sheet, the availability of interpreters at first court appearance and the publication of a pre-court multilingual document. When the Report was published in 1998, the following recommendations, ${ }^{4}$ regarding language and interpreting services were made:

i) the interpreter booking system be adopted state-wide;

ii) all police charge sheets use a prompt - Interpreter required for $1^{\text {st }}$ court appearance: Yes/No;

iii) training for police in the use of the new form and promotion of the benefits of the utilisation of interpreter services;

iv) training for all relevant local court staff on the effective use of interpreters in interviews and in the court;

v) training for all panel interpreters undertaking court work to ensure sufficient skills to work in a legal environment;

vi) publication of policy by the Ethnic Affairs Commission concerning complaint procedures;

vii) AG's to provide a specific budget for interpreting services;

viii) AG's to develop and issue policy and guidelines to ensure that accredited professional interpreters are provided with appropriate facilities and resources when at court; 
ix) revision of the Local Courts Practice and Procedure Manual so as to include information and guidelines on the provision of language and interpreter services (1998:49).

The results of these recommendations are discussed below.

\title{
2) Resourcing and associated logistical problems
}

Laster and Taylor noted that underlying the deficiencies that they identified in the language and interpreter services offered by the Victorian justice system 'are inadequacies in the resources for legal interpreting services and levels of pay for interpreters' (1994a:14). As stated, the CRC is the largest provider of court interpreters. The CRC employs 10 full time and more than 650 causal interpreters.

This appears to be a large number of interpreters but problems regularly arise in finding appropriately qualified interpreters for court work. The qualification required for a court interpreter is NAATI accreditation as an Interpreter (previously Level 3 under the old NAATI grades). Two main problems were reported by those interviewed. First, a language may be rare and there is difficulty in finding a suitable interpreter. In one extreme example an Australia-wide search was undertaken before a suitable interpreter was found. Where an appropriately qualified interpreter cannot be found, a lower level interpreter may be used. This is covered in the Guide to Local Court Policies and Procedures:

\begin{abstract}
In these circumstances Paraprofessional Interpreters (previously known as Level 2) may be accepted, but this is the lowest level of accreditation allowed and represents 'a level of competence in interpreting general conversation'. Accreditation at this level is not deemed sufficient to operate in specialised legal situations. When the Community Relations Commission advises the Court that it can only provide an interpreter with lower accreditation than Interpreter (formerly NAATI Level 3) for a hearing, the Presiding Magistrate should be consulted and if they agree to accept a less accredited interpreter, they should sign an agreement to this effect. For some minority languages, NAATI accreditation is not available (as they do not have assessors available who can undertake testing of applicants in that language) and NAATl will only issue a Certificate of Recognition. Recognition does not however have equivalent status with accreditation, nor does it specify a level of proficiency. Use of an interpreter, even with these minimum standards, is considered preferable to the use of family or friends to provide interpreting assistance (See Section 1 Interpreters, ltem 1.5).
\end{abstract}

In other cases, difficulties may arise because all qualified interpreters are already booked. This is particularly true for the more common languages. In one case outlined by a senior Local Court clerk, a large number of Korean sailors were faced with extradition proceedings to Victoria. In that single case 26 Korean interpreters were used which, as noted by the court clerk, likely accounted for all the qualified Korean interpreters in NSW. Such circumstances may again result in the use of a paraprofcssional interpreter.

Apart from problems of finding an appropriate interpreter or enough interpreters for a case, there were a number of other problems identified by those interviewed. The most significant was where an interpreter had been booked for a period of time but due to overruns or adjournments could not continue due to other bookings. Continuity was therefore adversely affected if a new interpreter had to be found and, where problems arose in finding a replacement or having to wait until the current interpreter was available again, lengthy adjournments occurred. The DPP prosecutor noted that this was a real problem and that in one case there was even consideration given to subpocnaing the interpreter as a witness so as to ensure his continued presence at the trial. In fact, the DPP prosecutor stated that: 'All cases involving interpreters cause problems and inevitably lead to one or more adjournments'. 
A common problem reported at the Local Court level was locating interpreters in the court house when needed for a case. With the exception, of Burwood Court, ${ }^{5}$ none of the other courts visited had any specific physical space where interpreters could congregate. Court clerks reported court staff having to make loud calls for interpreters in the public areas when an interpreter was not in the court at the time a case commenced. It was noted that at Burwood Court this problem was alleviated by one of the clerical officers being the designated person to whom all interpreters must report and 'check-in'. At other courts, however, if the interpreter was not in court at the time his/her case was called there was no way of knowing if the interpreter had in fact arrived.

This lack of physical space also leads to other problems. Because interpreters were often waiting around in the public areas, they were regularly approached by the accused or witnesses involved in the case. In addition, other individuals in other cases might approach them for language assistance. One of the CRC officers noted that:

Court interpreters are (in effec1) civil servants. When they are in court they should be allowed to use the facilities currently enjoyed by the court staff there.

Interpreter's conditions at court are appalling. Their physical proximity to the accused, for example, is a real problem with the physical arrangements in the courtroom.

One of the Fairfield recommendations was that the Attorney General's Department develop and issue policy and guidelines to ensure that accredited professional interpreters are provided with appropriate facilities and resources when at court (Recommendation 2.12). It does appear that such resources and facilities have not been made available in all courts. The interpreter noted that court house facilities varied widely, the facilities in the older court houses being described as deplorable. The interpreter concluded that there was still considerable room for improvement in this area.

It was also reported that interpreters often only arrived at court just prior to their booking and then left immediately after. The Police and DPP prosecutors and Legal Aid counsel interviewed saw this as problem in terms of consultation with the interpreter before and after any hearing. Based on the tightness of the booking system, however, and noting that interpreters are only paid by the hour for actual court time, any additional consultation would have to be factored in and paid for. The fact that interpreters only turned up at court just prior to their case and left immediately after was also seen by court staff as justification for not providing permanent dedicated space for interpreters. In addition, office accommodation at many of the older courts made it impossible to allocate such space.

As noted above, the Fairfield Court Community Access Project Report made a number of recommendations with specific resource implications. Of the nine recommendations listed above, those with the most significant resource implications were:

i) the interpreter booking system be adopted state-wide;

ii) all police charge sheets use a prompt - Interpreter required for $1^{\text {st }}$ court appearance: Yes/No;

iii) training for police in the use of the new form and promotion of the benefits of the utilisation of interpreter services;

iv) training for all relevant local court staff on the effective use of interpretcrs in interviews and in the court; 
v) training for all panel interpreters undertaking court work to ensure sufficient skills to work in a legal environment;

vi) AG's to provide a specific budget for interpreting services.

While there is no assessment of the quality of the implementation of these recommendations, all with the exception of the last have been implemented. The use of the booking system, for example, is now well established and subject to a Memorandum of Understanding between the Attorney General's Department, CRC and Police. The Attorney General's Department (Workplace Development Unit) has developed the Language Link Resource Kit to assist staff in communicating with clients from a non-English speaking background and a specialist training program for interpreters, funded by the Attomey General's Department, is also in operation at the University of Western Sydney.

The reason given for the AG's not providing a specific budget to the courts is that the CRC provides, and accordingly pays for, the vast majority of court interpreters on a fee exempt basis. The need for funds over and above this is are accordingly extremely variable and as such a specific budgetary allocation is inappropriate.

\section{3) Professionalisation, education and training}

Laster and Taylor noted:

Interpreters in Australia are still not perceived to be competent and ethical professionals (1994a:14).

In the legal context, professionalisation was also necessary to overcome what Laster and Taylor saw as a subordinated role played by interpreters in the courtroom setting, subordinate that is to the positions of judge, magistrate and lawyers. The relationship between lawyers (including judges and magistrates) and interpreters is of obvious significance, and Laster and Taylor state that:

In practice, lawyers have relegated interpreters to the status of a mechanical device (1994b:79)

'Problems' that occur during the course of any proceedings involving an interpreter are therefore inevitably blamed on the interpreter. As stated by some of those interviewed, there is therefore a need to improve the quality of interpreting. What such opinions fail to adequately reflect, however, is the extremely complex nature of the role of the court interpreter in the translation of legal language and the ways in which it is used.

In any event, Laster and Taylor (1994a) concluded that education and training need to be of an appropriate standard to raise interpreters to a professional standard and that this would be assisted in the long term by the development of professional associations or societies.

All court interpreters in Australia must be NAATI accredited. Such accreditation can be obtained through individual testing or by successfully completing a NAATI approved course of study. There are four levels of accreditation. These are:

i) paraprofessional interpreter/translator;

ii) interpreter/translator;

iii) conference interpreter/advanced translator;

iv) senior conference interpreter/senior advanced translator. 
Interpreter/translator is the minimum requirement for professional interpretation or translation and accordingly for all court interpreters. As noted earlier lower level interpreters may be used at court where no higher grades are available. With regard to the interpreter/translator level, NAATl states that:

This represents the minimum level of competence for professional interpreting or translating. It may be regarded as the Australian professional standard. Interpreters are capable of interpreting across a wide range of subjects involving dialogues at specialist consultations. They are also capable of interpreting presentations by the consecutive mode.

The skills stated are:

- interpreting in both language directions for a wide range of subject areas usually involving specialist consultations with other professionals, e.g. doctor/patient, solicitor/client, bank manager/client, court interpreting;

- interpreting in situations where some depth of linguistic ability in both languages is necessary (See <http://www.naati.com.au/accreditation.html >).

While NAATI is a government body and controls all accreditation, it has no professional or industry role outside of this. The only Australian professional association for interpreters and translators is the Australian Institute of Interpreters and Translators (AUSIT) which was founded in 1987. Laster and Taylor noted that:

The Australian Institute of Interpreters and Translators (AUSIT) may, in time, become the industry's peak body, but it is still developing (1994:20).

Hale stated, however, that:

The main avenue by which most enter the interpreting profession in Australia today is by sitting a one hour NAATI examination, with no interpreting training required. The original objective in establishing NAATI was for it to be a provisional body that would set up a basic infrastructure to allow for a self-regulating professional entity to assume the responsibility for accreditation. It was also anticipated that ultimately all aspiring interpreters would enter the profession via the completion of degree courses (NAATl 1978). Unfortunately neither of these two objectives were ever met. Even though the Australian Institute for Interpreters and Translation (AUSIT) was founded in 1987 as the national professional association, NAATI continued to exist unchanged and unchallenged (Hale 2000:48-9).

Hale further noted that the continued testing by NAATI has made it very difficult for tertiary interpreter courses due to the direct competition of NAATI itself. Even though accreditation can be obtained by completing a NAATI approved course ${ }^{6}$ there is, as mentioned, no requirement that court interpreters, for example, hold tertiary qualifications in a particular language. In 1998, NAATI did stipulate the need for specialist courses in legal interpreting and published guidelines on this (Hale 2000:49). NAATI did not, however, see this as a requirement, nor would it lead to additional accreditation and, as such, one must question the viability of this proposal.

As mentioned above, the Fairfield Project recommended the introduction of a training program for legal interpreters in NSW. As a result, the Attomey General's Department of New South Wales commissioned the University of Western Sydney to provide 35 hours of specialist legal interpreting training to the interpreters employed by the then Ethnic Affairs Commission (now $\mathrm{CRC}$ ). Hale, who designed this course, states that:

Although this is a step in the right direction, thirty five hours of non-language specific training will not be sufficient to achieve the desired results (Hale 2000:50).

6 In NSW these are provided by a number of TAFE Colleges, Uni of Wollongong and UWS. 
There is no way of assessing this statement but it is noted that all CRC court interpreters are required to sit and pass this course if they are to continue to be employed by CRC. From a training and education perspective, this is a step in the right direction but it is a limited step. Laster and Taylor stated that: 'Legal interpreting is not a specialization in Australia' (1994a:33). Current NAATl approved courses and NAATI testing covers a broad range of disciplines of which law is only one.

\section{As Hale noted:}

Interestingly, none of the Reports ever written on interpreter services and quality has ever mentioned the need for research to inform the training courses' curricula and NAATI examinations. The lack of a research tradition in the field and of mandatory pre-service training are the most serious deficiencies in the interpreting profession in Australia (Hale 2000:51).

NAATI is very aware of these limitations. The NAATI officer interviewed stated that the current system of accreditation was far from ideal. What was required for initial entry into the profession was a tertiary qualification in translating and interpreting followed by testing. This should also be supplemented by continuing professional education and retesting, particularly where an interpreter left the profession for a period of time.

It was also noted that there was only a small number of tertiary providers of interpreter and translator courses. The languages offered in these courses were also seen as mismatched to community needs. The NAATI officer provided an example of this problem where Ethiopian was identified as a language with a substantial need in a certain area of Melbourne but there were no courses offered in this language.

NAATI testing would also appear to be in need of a major overhaul. Currently, the only requirements prior to testing are:

i) any degree or diploma;

ii) ability in foreign language and English at the same level.

The NAATI officer also stated that many applicants for the test had extremely poor English and this lead to a very high failure rate.

Even with such a high failure rate, the interpreter interviewed felt that there were large numbers of interpreters in the more common languages, for example Chinese and Vietnamese. The interpreter stated that this, coupled with low rates of pay, was leading to unethical behaviour and falling standards. One example of such uncthical behaviour was where interpreters would take bookings knowing that they were already booked and were supposed to allocate a full day to the original booking. This, he said, resulted from interpreters being booked for a 3 hour period (at $\$ 50$ for this period) regardless of whether the matter took the full 3 hours or only lasted 5 minutes. Where an interpreter was unable to comply with both bookings he or she would pass the second booking on to a colleague. This was said to be common practice and representative of other types of unethical conduct resulting from low pay.

\section{Codes of Conduct and Ethics}

Published codes of conduct and ethics are seen as a necessary characteristic of any profession.

The CRC has a Code of Conduct for interpreters and translators who it employs. This Code, however, is based on the AUSIT Code of Ethics so it is appropriate to talk initially about this document (see <hllp://www.ausit.org/ethics.pdf $>$ for a full version of the Code). 
Eight general principles are identified by the Code. These are; professional conduct, confidentiality, competence, impartiality, accuracy, employment, professional development, professional solidarity.

It is said that the Code obliges members to:

- respect their clients rights to privacy and confidentiality;

- decline to undertake work beyond their competence or accreditation levels;

- take responsibility for the work of people under their supervision;

- decline to mix promotional activity for clients with interpreting or translation work;

- guard against misuse of inside information for personal gain;

- guard against encroaching on the work of co-members;

- maintain professional detachment, impartiality and objectivity;

- refer to arbitration by the National Council of any dispute with other members and to accept the Council decision as binding.

The obvious shortfall in this Code, as an aspect of professionalisation, is that membership of AUSIT is voluntary. While the CRC has adopted the AUSIT Code as the basis for its Code of Conduct, membership of AUSIT is not a condition for CRC employment. Both the AUSIT and CRC Codes talk about infamous conduct as a breach of the codes but neither contains any specific detail of what results from a breach of the code. It is presumed that it could result in suspension or expulsion from AUSIT and it can result in removal from the employment list at CRC, but neither appears to have the effect of suspension or banning from practice. As noted by one of the CRC officers interviewed, there is no system of registration or licencing for interpreters although this has been discussed for more than a decade. In this regard it is also important to note that NAATI has no authority to withdraw accreditation. NAATI does receive complaints, however, and will contact the relevant interpreter to discuss these. AUSIT also receives complaints but only the CRC has a formal complaints procedure. This is discussed in the next section on Quality and accuracy.

\section{4) Quality and accuracy}

'Horror stories about inadequacies of legal interpreters abound', although as Laster and

Taylor note, they are often anecdotal (1994a:14).

While anecdotal, such stories are still important in how they impact on the professional status of court interpreters and the perception of those involved in the criminal justice process. All of those interviewed felt that interpreter quality and standards were falling. In fact, a significant catalyst for this study was the experience of one of the authors. In a Local Court matter in 2002, he had been asked to provide certain language assistance to the court in a case of extortion. The interpreter used by the police had translated a part of the defendant's statement so that it read that 'he went from place to place collecting money'. In fact, this should have been translated as him 'going from place to place to play mahjong'.

The District Court judge interviewed also mentioned a case in which he was involved which was aborted twice due to major interpretation inaccuracies and another in which the prosecution case actually collapsed for the same reason. 


\begin{abstract}
Hale notes that:
Court interpreters swear an oath before the commencement of any court assignment, to truly and faithfully interpret the evidence and all other matters before the court. However, the meaning of 'truly and faithfully' or accuracy of interpretation remains an illusive concept for most, interpreters and legal professionals alike. Many interpreters lack the theoretical training to make informed decisions about how to interpret accurately and rely solely or heavily on intuition. Most legal professionals lack knowledge of cross linguistic differences and therefore mistakenly believe faithfulness equates to literalness. (Hale 2003:1-2)
\end{abstract}

What is unknown is the extent of inaccuracy. Obviously there are the specific cases such as those outlined by the District Court judge but it is important to note that even these so-called 'horror stories' may well have only come to the attention of the court by chance. In some cases this may result from a communication from the accused, a witness or a relative or some other person who spoke the language who happened to be in the court at the time. In one example given this other person was another interpreter. In other cases concerns may arise where the judge, magistrate, prosecution or defence counsel suspects that the interpretation provided in court is inaccurate. A general example of this which was mentioned was where the accused or witness would give quite a lengthy reply to a question in the foreign language but the English translation was very brief. It was felt that in such circumstances the interpreter was summarising or paraphrasing the response and that such an approach could also be used in translating the initial question as well. A number of those interviewed saw this as not only a significant quality issue, but also one that clearly affected the professional status of interpreters. A number of those interviewed also felt that this was due to the poor English language skills of the interpreter. In addition, it was noted that this 'cutting corners' approach by interpreters was an aspect of the system itself in that the completion of a case was the main priority rather than possible due process concerns.

This is not to say that inaccuracy is endemic or commonplace. On the contrary, the judge, magistrate, DPP prosecutor, police prosecutor and private barrister stated that they were satisfied with the quality of the majority of court interpreters they had come into contact with.

\title{
Complaints
}

The $\mathrm{CRC}$ has a formal complaints procedure with regard to its provision of court interpreters. Complaints are communicated to the CRC by the court clerks or registrars who have the responsibility of signing an interpreter's work sheets. Clerks are able, through this process, to provide feedback and comments on an interpreter's performance. One CRC officer interviewed noted that it was through this process that the CRC would become aware of any trial which was aborted or collapsed due to interpreter inaccuracy. Courts could also send a transcript of a case to the CRC and request that it be checked by another interpreter. If complaints were substantiated or interpreters were found to be in breach of the CRC Code of Conduct, they could be suspended or removed from the CRC's list of casual interpreters. As the CRC operates on the basis of 12 month terms of casual employment, such action could result in an interpreter not receiving any CRC work for a considerable period. What is unknown is the extent to which the CRC has exercised such action. This is important because the apparent shortage of good qualified court interpreters appears to lead to poor quality individuals being retained. The interpreter commented that the complaint system was ineffective. He noted that there were few complaints and litte follow-up on those received. In his opinion, the small number of complaints was, however, not indicative of a quality service but rather a product of the lack of any real mechanism for quality control. 


\section{Conclusion}

The purpose of the research outlined in this article was to assess the current issues affecting the use of court interpreters in the NSW criminal justice system. The research is preliminary, but a number of conclusions are possible based on the findings.

First, from an information perspective, there has been no research in NSW which has sought to analyse the use of interpreters in any aspect of the justice system. In 1990, it was noted that:

It is surprising that in the multicultural Australia of today there is so little material available on the evidential and other issues relating to the use of interpreters in the law ... This lack of material is no doubt a reflection of the wider apparent lack of appreciation within the justice system and the legal profession of the importance of language and the nature and proper use of professional interpretation (Roberts-Smith, QC 1990:36).

The only major research on language interpreters is the excellent, but limited, project undertaken by Laster and Taylor which forms the basis of their book, Interpreters and the Legal System (1994a). Despite the many recommendations put forward in this book, the many reports, agreements (in the form of Memorandums of Understanding) between government departments and trial projects, the situation in NSW today 'remains only partially better than it was thirty years ago' (Hale 2000:48).

The article identifies four headings under which the current state of the NSW court interpreter service can be assessed. These are:

1. Access and the right to an interpreter.

2. Resourcing and associated logistical problems.

3. Professionalisation, education and training.

4. Quality and accuracy.

These categories are not mutually exclusive. One may have the right to an interpreter but this is of little significance if, for example, a suitable interpreter cannot be found, or, even if available, is of poor quality. While access to and equity in the justice system are recognised, the reality is that these goals are not being met. Laster and Taylor (1994) are correct in noting that there appears to be little appreciation of the fact that interpreter services are likely most needed in legal settings prior to or outside of any court appearance. The focus on court interpreters, accordingly, diverts attention from these perhaps greater areas of need. But even focusing just on the provision of court interpreters, it is apparent that the system is falling short of any true notions of access and equity. This is particularly true in the Local Courts where the so-called 'sausage factory' approach to the dispensation of justice is in itself a significant obstacle to the provision of appropriate language services.

The information provided by those interviewed suggests that there are insufficient qualified court interpreters to meet the need. At the Local Court level, for example, there is even provision in the Practice and Procedure Manual for the approach to be taken where $\mathrm{CRC}$ are unable to provide an accredited court interpreter. It is also evident that relatives and friends are still used to assist the court in interpreting aspects of the process to the accused or a witness. It is clear, however, that any evidence of insufficient resourcing is, like many other aspects of the provision of court interpreter services, largely anecdotal. There is also a lack of basic statistical information on, for example, the number of court interpreters booked for criminal cases, the foreign languages involved in such cases and any impact on trial procedure. As noted, the next stage of our research is to undertake a major review of the NSW court interpreter scrvice and an important part of this will be the collection of certain basic statistical information. 
Laster and Taylor saw the solution to the many and varied problems with the provision of interpreter services in Australia's justice system as lying largely with the creation of an established and recognised interpreter profession. Simply claiming that there is such a profession is, as they say, insufficient evidence that such a profession actually exists (1994a:15). Laster and Taylor describe the Australian approach here as generalist, as compared, for example, to the specialist approach in the USA (1994a:31-36). In this sense, interpreters appear to have acquiesced to the wishes of the lawyers in their role as a simple conduit between the lawyer and the witness or defendant. Mechanical literacy is accordingly emphasised by both the lawyer and interpreter. Interpreters, however, appear ill-equipped to question such a role and Laster and Taylor's 1994 conclusion remains valid:

As a new 'profession', interpreting lacks both the knowledge and power base from which to challenge the imposed boundaries of its jurisdiction. Interpreters' unwillingness to critique the conduit metaphor is also a product of lack of professional organization (1994a:85).

The creation of AUSIT is a positive step but, as noted, membership is not compulsory. Nor can it be said that there exists any specialisation in interpreting and transiating, particularly in the legal arena.

As part of professionalisation, it is imperative that the current approach to the accreditation, education and training of interpreters be reviewed. Apart from a change in the labeling of the various interpreter grades there has been little change to the accreditation process. The introduction of the mandatory training program offered by UWS for court interpreters is a positive step, as are other courses such as that offered by Macquarie University, ${ }^{7}$ but as noted by Hale, it is still not enough. The interpreter commented, for example, that many current interpreters are simply unable to perform the job required because they lacked the skills required. In his view, such skills would be acquired through an initial tertiary qualification, on the job experience and a program of continuing education.

The evidence may be anecdotal but all of those interviewed expressed the view that the quality and standards of court interpreters were falling. It is evident at this preliminary stage that confidence in the quality and standards of court interpreters is directly linked to appropriate education qualification and training which in turn forms the basis for accreditation and entry into an interpreter profession.

Softic notes that training is only one issue and that there is a need to understand the environment in which interpreters work, and are used and exploited by the system (1993). Here it is evident that there continues to be problems with simple matters such as the provision of adequate office or other space for interpreters when at court. Failure to provide such resources also reflects the relative position of interpreters in the hierarchy of the justice system and the extent to which they are afforded professional status and recognition. The interpreter noted that many court personnel were unfamiliar with how to deal with an interpreter attending the courts and felt that such staff did not treat interpreters with the same respect that they accorded lawyers. This was in comparison to lawyers who in the interpreter's experience did treat interpreters with respect.

Laster and Taylor (1994a) and Hale (2000) conclude that the goal of access and equity has not been met. It is believed that the main reason for this is that the Australian justice system itself has underestimated the importance of language interpretation. This, in turn, has had negative consequences on the existence of sufficient numbers of qualified 
interpreters, their education and training and the ultimate quality of service. Such underestimation could also be explained by a lack of real commitment to the principle of access and equity. The use of interpreters in criminal trials, for example, appears to be seen by many as an unwelcome interference in the smooth running of the system. Hale also believes that:

...one reason for the insufficient use of interpreter services, is the service providers' overestimation of the client's ability to speak English (Hale 2000:53).

Such overestimation, however, may not be so much an example of misjudgment as it is an example of the lack of commitment to true 'access and equity'. The political response has been largely instrumentalist through improvement to the processes through which language assistance is provided in the courts.

(I)nterpreting can be tacked on at a minimal cost to make good law's claim to be dealing fairly with NESB people (Laster \& Taylor 1994b:90).

In this regard, Laster and Taylor correctly state that concentrating on court interpreters undermines a consideration of language assistance in non-court and non-legal settings and that even 'a thetorical commitment to "access and equity" does not come cheaply' (1994a:41).

\section{Cases}

Adamopoulos v Olympic Airways SA [1991] 25 NSWLR 75.

Deitrich v R (1993) 109 ALR 385.

Lee Kun $\vee R[1916] 1 \mathrm{~KB} 337$.

Ngyuen, Ex parte [1998] HCA 73.

\section{References}

Australian Law Reform Commission (1992) Multiculturalism and the Law Report No.57, AGPS, Canberra.

Berk-Seligson, S (1990) The Bilingual Courtroom. Court Interpreters in the Judicial Process, Chicago University Press, Chicago.

Bird, G (1993) The Process of Law in Australia, $2^{\text {nd }}$ ed, Butterworths, Sydney.

Commonwealth Attorney General's Department (1991) Access to Interpreters in the Australian Legal System, AGPS, Canberra.

Cook, M, Eades, D \& Hale, S (eds) (1999) 'Special Issue on Legal Interpreting', Forensic Linguistics, Vol 6, no 1.

Hale, S (2003) 'What does "to fully and faithfully interpret the evidence" mean?' conference paper presented at the Interpreters and Legal Professionals Working Together in Courts and Tribunals Conference, 21 March, UNSW.

Hale, S (2000) 'The Discourse of Court interpreting: An analysis of the discourse practices of the law, the Spanish speaking witness and the interpreter', PHD Thesis, Macquarie University. 
Hale, S (2001) 'How are Courtroom Questions Interpreted? An Analysis of Spanish Interpreters' Practices' in Mason, I (ed) Triadic Exchanges: Studies in Dialogue Interpreting, St. Jerome, Manchester.

Laster, K (1990) 'Access to Interpreters', Legal Service Bulletin, vol 15, pp 227-8.

Laster, K (1990) 'Legal Interpreters: Conduits to Social Justice', Journal of Intercultural Studies, vol 11, pp 15-32.

Laster K \& Taylor V (1993) "The Compromised "Conduit": Conflicting Perceptions of Legal Interpreters', conference paper presented at The Criminal Justice System in a Multicultural Society, Australian Institute of Criminology, Melbourne, 4-6 May.

Laster, K \& Taylor, V (1994a) Interpreters and the Legal System, Federation Press, Leichhardt.

Laster, K \& Taylor, V (1994b) "Technocratic Multiculturalism: Lawyers "Use" Interpreters', Law in Context, vol 12, no 1, pp 76-96.

Law Society of NSW (1996) 'Guide to Best Practice for Lawyers Working with Interpreters and Translators in a Legal Environment', Sydney.

Mikkelson, H (1998) 'Towards a redefinition of the role of the court interpreter' Interpreting, vol 3, no 1, pp 21-45.

National Accreditation Authority for Translators and Interpreters (NAATI) (2003) 'Concise Guide for Working with Translators and Interpreters in Australia', NAATI Ltd.

NSW Attorney General's Department (nd) 'Guide to Local Court Policies and Procedures', Section 1 Interpreters (Intranet).

NSW Government (1993) 'Charter of Principles for a Cuiturally Diverse Society', Sydney.

Popovic, J (1993) 'Migrants and Crime - A Magistrates Perspective', conference paper presented at The Criminal Justice System in a Multicultural Society, Australian Institute of Criminology, Melbourne, 4-6 May.

Robinson, L (1994) Handbook for Legal Interpreters, Law Book Company, Sydney.

Sin Kin Kui \& Djung, J (1994) 'The Court Interpreters' Office', in Gaylord, M \& Traver, $\mathrm{H}$, Introduction to the Hong Kong Criminal Justice System, Hong Kong University Press, Hong Kong.

Softic, S (1993) 'Interpreters: The Quiet Achievers', conference paper presented at The Criminal Justice System in a Multicultural Society, Australian Institute of Criminology, Melbourne, 4-6 May. 